\title{
PENGARUH SENAM LANSIA TERHADAP PENURUNAN TINGKAT NYERI PUNGGUNG BAWAH PADA LANSIA DI PUSKESMAS HELVETIA MEDAN
}

\author{
Johani Dewita Nasution \\ Jurusan Keperawatan Poltekkes Kemenkes RI Medan
}

\begin{abstract}
Elderly gymnastic is a movement with the regular rhythm, directed and planned followed by the elderly in order to increase the physical functional. This research aims to study the influence of the elderly gymnastic to the lower back pain to the elderly at the Puskesmas Helvetia Medan. This research is Quasy Experimental design using Pretest-Posttest Design in which this research was conducted by initial observation (pretest) before intervention. The number of population in this research is 95 persons of elderly. The sample is determined by accidental sampling. The result of research indicates that before the elderly gymnastic, the lower back pain in medium level is for 26 respondents (100\%) and after the elder gymnastic, the number of respondent with the medium lower back pain is 15 respondents (57.7\%). The result of statistical test it indicates the significant result to the minimization of the lower back pain with $P=0.000(P<0.005)$. Based on this ressults it conclude that the elder gymnastic influence the minimization of the lower back pain to the elderly. It is suggested to the health service to provide the elderly with gymnastic that can minimize the lower back pain to the elderly
\end{abstract}

Keywords : Elderly Gymnastic, Pain level

\section{A. Latar Belakang}

Semakin bertambahnya jumlah lansia di banyak negara, termasuk negara berkembang seperti indonesia, akan mengubah profil kependudukan nasional maupun global. Kalau pada tahun 2000, jumlah lansia di dunia sebanyak 426 juta atau $6,8 \%$ dari total penduduk penghuni planet bumi ini, maka pada 25 tahun pertama abad ke 21 atau tahun 2025, diperkirakan akan meningkat dua kali lipat menjadi 828 juta orang atau 9,7\% dari jumlah penduduk dunia. Bahkan perkiraan lain menyebutkan, pada tahun 2025 itu total lansia mencapai 1,2 miliar orang (Hutapea, 2005).

Berdasarkan laporan data penduduk internasional yang dikeluarkan oleh Bureau of census Amerika Serikat, Indonesia dalam kurun waktu 1990 2025 akan memiliki kenaikan jumlah penduduk lansia sebesar $414 \%$, artinya, ini yang paling tinggi di dunia. Diduga pada tahun 2015, jumlah lansia di indonesia akan mencapai 24,4 juta orang atau $10 \%$ dari seluruh penduduk indonesia saat itu dan pada tahun 2020 akan mencapai sebesar 30 juta orang (Hutapea, 2005). Berdasarkan data Badan Pusat Statistik (BPS) pada tahun 2007, jumlah lansia di Indonesia mencapai 18,96 juta orang. Dari jumlah tersebut $11,16 \%$ di antaranya berada di Provinsi Jawa tengah atau peringkat nomor dua daerah paling tinggi jumlah lansia setelah Yogyakarta (Media Indonesia Nasional, 2009).
Penduduk lansia merupakan salah satu kelompok penduduk yang potensial menjadi masyarakat rentan, sehingga perlu diciptakan suatu kondisi fisik maupun nonfisik yang kondusif untuk pembinaan kesejahteraannya. Pada hakikatnya, kaum lansia di berbagai negara termasuk Indonesia tidak hanya diharapkan berumur panjang, namum juga dapat menikmati masa tuanya dengan sehat, bahkan berdayaguna bagi pembangunan. Oleh sebab itu, perlu suatu strategi khusus untuk menangani mereka sejak dini. (Hutapea, 2005). Salah satu masalah fisik seharihari yang sering ditemukan pada lansia adalah nyeri punggung bawah atau LBP (Bandiyah, 2009).

Nyeri punggung bawah atau Low Back Pain (LBP) merupakan manifestasi keadaan patologik yang dialami oleh jaringan atau alat tubuh yang merupakan bagian punggung atau yang ada di dekat punggung (Idyan, 2008). Gejala nyeri punggung bawah (Low Back Pain) bervariasi mulai dari rasa nyeri ke sensasi tertusuk atau tertembak. Rasa sakit ini dapat membuat penderita sulit untuk bergerak atau berdiri tegak. Nyeri punggung akut datang dengan tiba - tiba, biasanya setelah cedera akibat olahraga atau mengangkat beban berat. Nyeri yang berlangsung lebih dari tiga bulan di anggap kronis. Jika rasa sakit penderita tidak membaik dalam waktu 72 jam, maka harus berkonsultasi dengan dokter (Mujianto, 2013). LBP merupakan keluhan yang berkaitan erat dengan usia. Biasanya nyeri ini mulai 
dirasakan pada mereka pada usia dekade kedua dan insiden tinggi dijumpai pada dekade kelima (Mardjono \& Sidharta, 2008). Jadi mereka yang berusia 40 tahun ke atas memerlukan informasi pengetahuan tentang kegiatan olahraga atau kesegaran jasmani (Setiabudhi \& Hardywinoto, 2005).

Low Back Pain (LBP) sering dijumpai dalam praktek sehari - hari, terutama di negara - negara industri. Diperkirakan $70-85 \%$ dari seluruh populasi pernah mengalami episode ini selama hidupnya. Prevalensi tahunannya bervariasi dari $15-45 \%$, dengan point prevalence rata - rata 30\% (Sadeli dan Tjahjono 2005). Data epidemiologi mengenai LBP di Indonesia belum ada, namum diperkirakan $40 \%$ penduduk pulau jawa Tengah berusia diatas 65 tahun pernah menderita nyeri punggung, prevalensi pada laki - laki 18,2\% dan pada wanita 13,6\%. Insiden berdasarkan kunjungan pasien ke beberapa rumah sakit di Indonesia berkisar antara 3-17\% (Sadeli dan Tjahjono, 2005).

Nyeri punggung (low back pain) apabila tidak ditangani tidak hanya menyebabkan nyeri dan ketidaknyamanan yang berkepanjangan, frustasi dan distress tetapi juga dapat mengakibatkan cacat seumur hidup (Mujianto, 2013). Gangguan pada sistem muskuluskeletal dapat memberikan dampak immobilitas fisik pada lansia. Penurunan fungsi tubuh pada lansia akan mengakibatkan permasalahan gangguan gerak dan fungsi lansia. Lansia mengalami penurunan fungsi jalan, penurunan fungsi keseimbangan, penurunan kemandiriandalam aktifitas kehidupan sehari - hari dan penurunan kemampuan fungsional (Martono, 2009).

Kemampuan fungsional lansia merupakan kemampuan lansia dalam melakukan gerak untuk beraktivitas termasuk kemampuan mobilitas dan aktivitas untuk memenuhi kebutuhan diri lansia termasuk aktivitas perawatan diri (Azizah, 2011).

Latihan peregangan atau senam akan berdampak lebih baik dibandingkan dengan bed rest. Penderita Low Back Pain (LBP) mungkin akan beristirahat satu sampai dua hari ketika nyeri muncul tetapi setelah jangka waktu tersebut nyeri biasanya akan semakin memburuk karena badan tidak aktif. Tanpa latihan dan gerakan, otot punggung dan struktur tulang belakang menjadi tidak terkondisi dengan bagus dan kurang mampu menopang tulang belakang apalagi tungkai kaki. Hal tersebut dapat menyebabkan cidera kembali dan spasme yang akan menimbulkan nyeri (Sadeli \& Tjahjono, 2005).

Senam dapat membantu kesehatan disekitar tulang belakang dimana gerakan - gerakan dapat membantu pertukaran nutrisi dan cairan dalam disk dan mencegah tekanan pada saraf ischiadicus. Senam juga dapat membantu meningkatkan fleksibilitas otot - otot yang menegang dan mempengaruhi saraf. Latihan senam dapat membantu menjaga tubuh tetap sehat dan bugar dalam jangka waktu panjang. Selain iu senam juga dapat meningkatkan sirkulasi darah dan meningkatkan oksigenisasi sel sehingga dapat mengurangi gejala kekurangan oksigen sel yang pada akhirnya mengurangi peningkatan asam laktat dan mengurangi nyeri (Ambar, 2009).

Dari penelitian Munns yang meneliti 40 orang lansia, yang 20 orang hanya sebagai pembanding saja dan 20 orang selanjutnya benar - benar dilatih, tenyata setelah 12 minggu maka 20 lansia yang di latih mengalami perbaikan hampir di seluruh persendiannya yaitu, pada leher, bahu, pergelangan tangan, lutut, dan pergelangan kaki, sebanyak $8-48 \%$ (Margatan, 2000).

Berdasarkan survey pendahuluan data yang dilakukan di Puskesmas Helvetia Medan jumlah lansia yang mengalami nyeri punggung bawah (LBP) adalah sebanyak 95 orang lansia.

Berdasarkan data hasil penelitian di atas sehingga peneliti tertarik untuk melakukan penelitian tentang Pengaruh senam lansia terhadap tingkat nyeri punggung bawah pada lansia di Puskesmas Helvetia Medan.

\section{B. Desain Dan Metode Penelitian}

Desain dalam penelitian ini adalah Quasy Experimental dengan menggunakan metode pre test post test design. Penelitian ini dilakukan dengan cara melakukan pre test (pengamatan awal) terlebih dahulu sebelum diberikan intervensi. Sesudah diberikan intervensi, kemudian dilakukan kembali post test (Alimul, 2007).

\section{Hasil Penelitian}

1. Analisa Univariat

Analisa univariat dilakukan untuk menghasilkan distribusi, frekuensi, dari masing masing variabel. Dari lembar observasi, karakteristik responden berupa data umum lansia meliputi umur, jenis kelamin, penurunan tingkat nyeri sebelum dan sesudah dilakukan senam lansia.

\section{a. Karakteristik}

Tabel 4.1. Distribusi Frekuensi

Karakteristik Responden Yang Mengalami Nyeri Punggung Bawah Di Puskesmas Helvetia Medan Tahun 2015

\begin{tabular}{clcc}
\hline No. & Karakteristik & F & $\%$ \\
\hline 1 & Umur & & \\
& $-\quad 60-65$ & 13 & 50 \\
& $-\quad 66-70$ & 13 & 50 \\
2 & Jenis Kelamin & & \\
& $-\quad$ Laki-Laki & 11 & 42,3 \\
& $-\quad$ Perempuan & 15 & 57,7 \\
\hline & TOTAL & 26 & 100 \\
\hline
\end{tabular}

Berdasarkan Tabel 4.1 di atas dapat dilihat bahwa responden adalah berusia $60-65$ tahun sama banyaknya dengan responden berusia 66 - 70 tahun yaitu 13 orang (50\%), dan mayoritas responden berjenis kelamin perempuan yaitu sebanyak 15 orang $(57,7 \%)$ dan minoritas 
responden berjenis kelmin laki-laki yaitu sebanyak 11 orang $(42,3 \%)$.

\begin{tabular}{|c|c|c|c|c|c|c|c|}
\hline & \multicolumn{7}{|c|}{ Tingkat Nyeri Sebelum dan Sesudah Senam } \\
\hline & \multirow[t]{4}{*}{ Tabel 4.2. } & \multirow{4}{*}{\multicolumn{3}{|c|}{$\begin{array}{l}\text { Distribusi } \\
\text { Tingkat } \\
\text { Sebelum } \\
\text { Dilakukan } \\
\text { Puskesmas } \\
\text { Tahun 2015 }\end{array}$}} & \multirow{4}{*}{\multicolumn{3}{|c|}{$\begin{array}{cr}\text { Frekuensi } & \text { Proporsi } \\
\text { Nyeri } & \text { Responden } \\
\text { Dan } & \text { Sesudah } \\
\text { Senam Lansia Di } \\
\text { Helvetia } & \text { Medan }\end{array}$}} \\
\hline & & & & & & & \\
\hline & & & & & & & \\
\hline & & & & & & & \\
\hline \multirow[t]{2}{*}{ No } & \multirow{2}{*}{\multicolumn{2}{|c|}{ Tingkat Nyeri }} & \multirow[t]{2}{*}{ Skor } & \multicolumn{2}{|c|}{ Sebelum } & \multicolumn{2}{|c|}{ Sesudah } \\
\hline & & & & $\mathrm{F}$ & $\%$ & $\mathrm{~F}$ & $\%$ \\
\hline 1 & Nye & & $1-3$ & - & 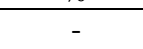 & 11 & 42,3 \\
\hline \multirow[t]{2}{*}{2} & Nyeri Seda & & $4-6$ & 26 & 100 & 15 & 57,7 \\
\hline & TOTAL & & & 26 & 100 & 26 & 100 \\
\hline
\end{tabular}

Berdasarkan Tabel 4.2 dapat diketahui bahwa tingkat nyeri punggung bawah pada responden sebelum dilakukan senam lansia berasal dari skala nyeri sedang yaitu sebanyak 26 orang (100\%). Dan dapat diketahui bahwa tingkat nyeri punggung bawah pada responden sesudah dilakukan senam lansia dengan mayoritas nyeri sedang sebanyak 15 orang $(57,7 \%)$ dan minoritas nyeri ringan sebanyak 11 orang $(42,3 \%)$.

\section{Analisa Bivariat}

Analisa Bivariat dengan uji analisa pair t-test didapatkan hasil sebagai berikut:

Tabel 4.3. Perbedaan Tingkat Nyeri Responden Sebelum dan Sesudah Dilakukan Senam Lansia Di Puskemas HelvetiaMedan Tahun 2015

\begin{tabular}{lll}
\hline Tingkat Nyeri & Mean & SD \\
\hline Sebelum Senam Lansia & 3,00 & 0.00000 \\
Sesudah Senam Lansia & 2,57 & 0.50383 \\
\hline
\end{tabular}

Pada tabel 4.3. dari analisis statistik dapat dilihat bahwa perbedaan sebelum dan sesudah diberikan senam lansia yang mengalami nyeri punggung dengan nilai Mean sebelum senam lansia 3,00 nilai SD 0,00000 dan sesudah senam lansia 2,57 nilai SD 0,50383 dapat dilihat bahwa terjadinya penurunan tingkat nyeri punggung bawah setelah dilakukan senam lansia.

Tabel 4.4. Hasil Uji Paired T-test Perbedaan Tingkat Nyeri Punggung Bawah Sebelum dan Sesudah Dilakukan Senam Lansia Di Puskesmas HelvetiaMedan Tahun 2015

\begin{tabular}{lcccccc}
\hline Variabel & $\mathrm{P}$ & $\mathrm{t}$ & $\mathrm{M}$ & $\mathrm{SD}$ & \multicolumn{2}{l}{$\begin{array}{l}\text { Interval } \\
\text { Kepercayaan 95\% }\end{array}$} \\
\cline { 4 - 6 } & & & & & \multicolumn{3}{c}{ Lower } & Upper \\
\hline $\begin{array}{l}\text { Sebelum } \\
\text { dan }\end{array}$ & 0.000 & 4.28 & 0.42 & 0.50 & 0.62 & 0.21 \\
sesudah & & & & & & \\
senam & & & & & & \\
lansia & & & & & & \\
\hline
\end{tabular}

Pada tabel 4.4. dapat dilihat bahwa hasil analisis statistik uji Paired t-test adanya perbedaan sebelum dan sesudah diberikan senam lansia dengan nilai $\mathrm{t}=4,28$ dengan nilai rata - rata $\mathrm{M}=0,42(\mathrm{SD}=$ $0,50)$ dimana nilai perbedaan tersebut dengan nilai rentang $0,62=0,21$ pada taraf nilai kepercayaan $95 \%$ yang mengalami nyeri punggung mengalami penurunan dengan nilai signifikan $\mathrm{P}=0,000(\mathrm{P}<0,005)$.

\section{Pembahasan}

Penelitian ini membahas tentang Pengaruh Senam Lansia Terhadap Penurunan Tingkat Nyeri Punggung Bawah Pada Lansia Di Puskesmas Helvetia Medan. Pengukuran skala nyeri dilakukan sebelum dan sesudah pemberian senam lansia.

Hasil pengamatan peneliti menunjukkan bahwa lansia yang menderita nyeri punggung bawah di Puskemas Helvetia Medan yang mengalami nyeri sedang sebelum diberikan senam lansia sebanyak 26 orang. Dan dari hasil observasi, Lansia biasanya mengeluh nyeri punggung akut maupun kronik (berlangsung lebih dari 2 bulan tanpa perbaikan), nyeri punggung bawah memburuk saat berdiri atau duduk, kaku pada pagi hari, nyeri sering merata dan menyebar. Kadang-kadang, dasar organik nyeri punggung bawah tak dapat ditemukan. Kecemasan dan stres dapat membangkitkan spasme otot dan nyeri.

Menurut teori, faktor resiko utama terkena nyeri punggung bawah adalah pada lansia yang berumur 60 tahun ke atas. Gejala nyeri punggung bervariasi mulai dari rasa nyeri ke sensasi tertusuk atau tertembak. Rasa sakit ini dapat membuat penderita sulit untuk bergerak atau berdiri tegak. Nyeri punggung akut datang dengan tiba - tiba, biasanya setelah cedera akibat olahraga atau mengangkat beban berat. Nyeri yang berlangsung lebih dari tiga bulan di anggap kronis. Jika rasa sakit penderita tidak membaik dalam waktu 72 jam, maka harus berkonsultasi dengan dokter (Mujianto, 2013). Dan peneliti menemukan kenyataan yang sesuai dengan teori tersebut, bahwa $100 \%$ responden yang berumur 60 tahun keatas beresiko menderita nyeri punggung bawah.

Tindakan untuk mengatasi nyeri dapat dilakukan dengan tindakan pengobatan farmakologis dan non farmakologis. Secara farmakologis meliputi analgetik narkotik digunakan untuk memutus lingkaran nyeri; relaksan otot dan penenang digunakan untuk membuat relaksasi pasien dan otot yang mengalami spasme, sehingga dapat mengurangi nyeri. Obat anti inflamasi seperti aspirin dan NSAID berguna untuk mengurangi nyeri. Dan secara nonfarmakologis terdiri dari berbagai tindakan penanganan secara fisik pemberian perilaku kognitif seperti distraksi, teknik relaksasi, dan terapeutik. Salah satu tindakan non farmakologis adalah pemberian senam lansia.

Dalam hal ini, peneliti ingin melihat penurunan tingkat nyeri punggung bawah dengan intervensi senam lansia pada lansia, karena selama ini pemberian terapi untuk penurunan tingkat nyeri hanya berfokus pada terapi farmakologi saja. Karena itu 
peneliti mencoba memberikan terapi non farmakologis yaitu pemberian senam lansia.

Senam lansia adalah serangkaian gerak nada yang teratur dan terarah serta terencana yang diikuti oleh orang lanjut usia yang dilakukan dengan maksud meningkatkan kemampuan fungsional raga untuk mencapai tujuan tersebut. (Santosa, 2010).

Peneliti memilih senam lansia karena merupakan salah satu alternative yang paling aman sekaligus mempunyai terapi yang bisa mengurangi penurunan tingkat nyeri. Oleh karena itu sering digunakan untuk meringankan nyeri (Koensoemardiyah, 2009).

Dari hasil penelitian yang dilakukan, sebelum diberikan senam lansia responden mengalami nyeri sedang yang sesuai dengan kriteria inklusi yaitu sebanyak 26 orang (100\%). Setelah diberikan senam lansia mayoritas responden mengalami nyeri sedang sebanyak 15 orang $(57,7 \%)$ dan minoritas yang mengalami nyeri ringan sebanyak 11 orang $(42,3 \%)$. Data diatas menunjukkan bahwa terjadinya penurunan tingkat nyeri setelah diberikan senam lansia.

Dari data diatas terdapat mayoritas responden dengan nyeri sedang sebanyak 15 orang $(57,7 \%)$ nyeri ini tidak berkurang dipengaruhi oleh beberapa faktor seperti aktifitas sehari- hari responden yaitu berkebun, menyuci, membersihkan rumah, mengangkat beban berat dan hanya tidur saja. Sedangkan minoritas responden yang mengalami penurunan tingkat nyeri punggung bawah sebanyak 11 orang $(42,3 \%)$ di karenakan responden sering melakukan senam lansia dirumah dengan mengikuti Standard Operational Prosedur (SOP) senam lansia yang diberikan oleh peneliti kepada responden.

Menurut asumsi peneliti, hasil penelitian sesuai dengan teori yang mengatakan bahwa manfaat dari latihan peregangan adalah mengoptimalkan gerak otot dan sendi, meningkatkan kebugaran jasmani, menurunkan nyeri punggung bawah, mengurangi risiko cidera otot dan sendi, dan mengurangi ketegangan dan nyeri otot (Depkes, 2003).

Data tersebut menunjukkan terjadi penurunan tingkat nyeri sesudah diberikan senam lansia. Dan hasil uji rata-rata untuk dua sampel berpasangan (paired sample t-test) yang digunakan untuk menunjukkan bahwa tingkat nyeri sebelum dan sesudah pemberian senam lansia berbeda secara signifikan yaitu $\mathrm{p}=0.000$ $(\mathrm{p}<0.05)$, artinya bahwa Ha diterima. Sehingga dapat dinyatakan bahwa pemberian senam lansia berpengaruh dalam menurunkan tingkat nyeri punggung bawah pada lansia.

Dari penelitian Munns yang meneliti 40 orang lansia, yang 20 orang hanya sebagai pembanding saja dan 20 orang selanjutnya benar - benar dilatih, tenyata setelah 4 minggu maka 20 lansia yang di latih mengalami perbaikan hampir di seluruh persendiannya yaitu, pada leher, bahu, pergelangan tangan, punggung bawah, lutut, dan pergelangan kaki, sebanyak $8-48 \%$ (Margatan, 2000).
Dari beberapa hasil penelitian serta teori di atas ternyata sejalan dengan hasil penelitian yang dilakukan oleh peneliti, bahwa pemberian senam lansia dapat mengurangi tingkat nyeri punggung bawah. Oleh karena itu perawat yang lebih banyak menghabiskan waktunya bersama lansia, seharusnya tidak hanya berkolaborasi dengan tenaga profesional lainnya tetapi dapat langsung memberikan intervensi keperawatan dan salah satunya adalah pemberian senam lansia.

\section{E. Kesimpulan}

Dari hasil penelitian yang dilakukan mengenai pengaruh senam lansia terhadap penurunan tingkat nyeri punggung bawah pada lansia di puskesmas Helvetia Medan maka didapat kesimpulan sebagai berikut:

1. Hasil pengukuran tingkat nyeri responden dengan menggunakan skala Bourbonis $(0-10)$ sebelum dilakukan senam lansia diperoleh bahwa seluruh responden mengalami tingkat nyeri sedang.

2. Hasil Pengukuran tingkat nyeri responden dengan menggunakan skala Bourbonis $(0-10)$ setelah dilakukan senam lansia di dapatkan sebanyak 11 responden yang mengalami tingkat nyeri ringan dan 15 responden mengalami nyeri sedang.

3. Berdasarkan analisis menggunakan komputerisasi dengan software analisis statistik ditemukan bahwa terdapat perbedaan nilai tingkat nyeri responden sebelum dan sesudah pemberian senam lansia, dimana nilai tingkat nyeri responden sesudah dilakukan senam lansia lebih rendah dibandingkan pada saat sebelum senam lansia. Selain itu hasil uji analisis statistik Paired t-test menunjukkan adanya perbedaan yang signifikan yaitu nilai $\mathrm{p}=0,000$ $(\mathrm{p}<0,005)$, sehingga dapat disimpulkan bahwa senam lansia berpengaruh dalam penurunan tingkat nyeri punggung bawah (low back pain).

\section{F. Saran}

A. Bagi tenaga kesehatan

Senam lansia terbukti memiliki pengaruh terhadap penurunan tingkat nyeri punggung bawah sehingga dalam pelaksanaan asuhan keperawatan terhadap nyeri khususnya low back pain tenaga kesehatan dapat memberikan senam lansia sebagai salah satu alternatif intervensi keperawatan secara non farmakologis.

\section{B. Bagi Puskesmas}

Pemberian senam lansia berpengaruh terhadap nyeri punggung bawah, oleh karena itu penelitian ini dapat dijadikan sebagai informasi kesehatan yang bertujuan untuk meningkatkan kemampuan dalam mengatasi nyeri selain itu senam lansia ini kepada keluarga dan masyarakat luas untuk meningkatkan kemandirian masyarakat dalam menegnai usaha kesehatan.

C. Bagi Institusi Pendidikan

Kepada institusi pendidikan keperawatan agar dapat lebih meningkatkan pengetahuan dan kemampuan mahasiswa dalam memahami pentingnya 
terapi non farmakologis terutama pemberian senam lansia dan terapi bekam pada lansia yang mengalami nyeri punggung bawah.

D. Bagi Peneliti Selanjutnya

Kepada peneliti selanjutnya agar hasil penelitian ini hendaknya dapat digunakan sebagai data awal ataupun informasi untuk pengembangan penelitian selanjutnya tentang pengaruh senam lansia terhadap penurunan tingkat nyeri punggung bawah pada lansia.

\section{Daftar Pustaka}

Azizah. (2011). Keperawatan Lanjut Usia. Yogyakarta: Graha Ilmu.

Aristo, (2007). Hubungan Tes Timed Up And Go Dengan Frekuensi Jatuh Pada Pasien Lanjut Usia Di Semarang. Jurnal: https://www.google.com. Diperoleh pada tanggal 27 Desember 2014.

Depsos. (2003). Perpustakaan Media Kebijakan Program Pelayanan Sosial Lansia. http://www.google.com, diperoleh pada tanggal 27 Oktober 2013.

Ediawati. (2012). Gambaran Tingkat Kemandirian ADL Dengan Risiko Jatuh Pada Lansia Di PSTW Mulia Jakarta Timur. jurnal http://lontar.ui.ac.id. Diperoleh pada tanggal 05 Januari 2015.
Menkokesra. (2005). Peran Lansia Agar Ditingkatkan. http://www.menkokesra.go.id. Diperoleh pada tanggal 8 Januari 2015.

Mujianto. (2013). Cara Cepat Mengatasi 10 Besar Kasus Muskuluskletal Dalam Praktik Klinik Fisioterapi: Trans Info Media, Jakarta.

Nogroho, W. (2012). Keperawatan Gerontik \& Geriatrik, edisi ke-3. Penerbit Buku Kedokteran. Jakarta: EGC.

Nursalam. (2008). Konsep \& Penerapan Metodologi Penelitian Ilmu Keperawatan. Jakarta: Salemba Medika.

Padila, (2013). Buku Ajar Keperawatan Gerontik. Penerbit Buku Keperawatan. Nuha Medika, Yogyakarta.

Qomariah, (2012). Masalah Jatuh Pada Lansia Faktor Risiko, Komplikasi (Brown, http://jurnal.lib.unair.ac.id, diperoleh tanggal 16 Januari 2015).

Siti Bandiyah, (2009). Lanjut Usia Dan Keperawatan Gerontik. Penerbit Buku Keperawatan. Nuha Medika, Yogyakarta. 